\title{
The dilemma of pesticide residues in fruits and vegetables in the Eastern Mediterranean Region
}

\author{
Philippe Verger ${ }^{1}$ and A. Basel Al-Yousfi ${ }^{2}$
}

${ }^{1}$ Advisor Food Safety, World Health Organization Regional Office for the Eastern Mediterranean Centre for Environmental Health Action (CEHA); ${ }^{2}$ Director, World Health Organization Regional Office for the Eastern Mediterranean Centre for Environmental Health Action (CEHA), Amman, Jordan (Correspondence to: A. Basel Al-Yousfi: alyousfia@who.int).

Citation: Verger P; Al-Yousfi AB. The dilemma of pesticide residues in fruits and vegetables in the Eastern Mediterranean Region. East Mediterr Health J. 2020;26(7):760-761. https://doi.org/10.26719/2020.26.7.760

Copyright (c) World Health Organization (WHO) 2020. Open Access. Some rights reserved. This work is available under the CC BY-NC-SA 3.0 IGO license (https://creativecommons.org/licenses/by-nc-sa/3.o/igo)

In the World Health Organization Eastern Mediterranean Region (EMR), over 100 million people fall ill every year from foodborne diseases, of whom an estimated 37000 die annually (disproportionally children). A number of studies have identified a clear relationship between occupational exposure to pesticides and a number of noncommunicable diseases (NCDs). For example, respiratory symptoms were reported in $65.9 \%$ of farmers exposed to pesticides in Pakistan (1); lymphoproliferative disorders following exposure to pesticides in Egypt (2); and hepatocellular carcinoma in Yemen with $73.7 \%$ of farmers having a history of chemical contact with insecticides or fertilizers (3). However, a challenging task regarding the burden of foodborne disease is the attribution to chemicals in food as a source for NCDs, since this requires long-term epidemiological and exposure monitoring data.

The World Health Organization Regional Office for the Eastern Mediterranean (WHO/EMRO) Centre for Environmental Health Action (CEHA) conducted a literature review regarding exposure to pesticides through diet. The review identified 25 studies carried out between 2005 and 2019 in the EMR that reported analytical results for pesticide residues in fruit and vegetables (4). As a first result, the review reported that international Maximum Residue Limits (MRLs) were exceeded in up to $61 \%$ of the samples. In addition, $87 \%$ of the 6727 samples analyzed saw the exceeded MRL rate higher than $7 \%$; as a comparison, only $0.78 \%$ and $1.4 \%$ of samples tested in the United States of America (5) and in the European Union (6) exceeded the regulatory limits, respectively. The second issue revealed is the repeated detection of old organo-chlorine pesticides, such as aldrin/dieldrin, chlordane, DDT, endrin and heptachlor, all of which have been banned by the international community and listed in the Stockholm Convention (7) as Persistent Organic Pollutants (POPs).

The traditional approach of controlling and managing the disease burden of environmental risks, including foodborne diseases, relied on treating the symptoms rather than emphasizing deterrence and mitigation of the root causes. Therefore, a multisectoral shift in the approach is needed to focus on upstream preventive and corrective interventional actions for minimizing environmental risks. Since many aspects of food safety services are situated outside the mandate of a single agency and the health sector per se, the integrated cross-sectional framework is steered by the Health in All Policies (HiAP) and Health for All by All principles (8). Within the overarching approach of the "Farm-toFork" strategy (9), the work of CEHA shall focus on supporting the leadership role of the public health sector in regulating and monitoring environmental health factors (10), promoting preventive interventions, and in particular catalyzing adequate food safety services and actions by pertinent sectors (e.g. agriculture, water, trade, transport, etc.).

WHO, in collaboration with Food and Agricultural Organization (FAO) of the United Nations, organized in 2020 an expert consultation to discuss the results of the literature review and to provide UN partners and national authorities with recommendations on the way forward to tackle this dilemma. A regional panel of multisectoral experts coming from versatile relevant back grounds such as laboratory experts, chemical exposure experts, researchers, NCDs and other specialists, was formed to assess the situation and magnitude of pesticides and insecticide residues on fruits and vegetables, and the potential short and long-terms public health impacts. Major gaps were identified due to the lack of harmonization of regulations within the Region; in particular, the participation of EMR countries in the Codex Alimentarius (11) and the implementation of codex standards, which appeared ad hoc and inadequate.

At national levels in most countries in the EMR, it was noted that there was evidence of poor traceability systems and a shortage of resources and efforts to implement an integrated pesticide management involving farmers, food exporters, retailers, and importers of pesticides. An additional obstacle to improving farmer practices was the absence of chemicals' safety awareness, the distribution of small farm-holdings within EMR countries, and the deficient organization/coordination between stakeholders to ensure sufficient support.

Thus, it is recommended that EMR countries and international organizations undertake several measures to mitigate these obstacles, namely: implement an effective legal framework; improve health workforce recruitment; implement monitoring, surveillance and response functions; effective interaction with 
stakeholders; and implement an evidence/risk base policy.

Populations in the Region are often exposed to pesticide residues. Exposure to pesticides may include illegal (banned and or restricted internationally) or obsolete pesticides, as well as legal pesticides evaluated by international organizations. Excessive human exposure to certain types of pesticides may lead to adverse health effects, such as increased cancer risk, reproductive disorders, alteration of the immune system, neurobehavioural impairment, endocrine disruption, genotoxicity and an increase in birth defects, among others.

The responsibility to govern pesticide production, usage and management of health effects is often shared by several government offices, including ministries of industry, environment, agriculture and health. It is therefore necessary to maintain a high level of coordination between all involved ministries in order to establish a coherent and comprehensive regulatory framework to fully control human exposure to pesticides used in agriculture (12,13). Data from monitoring programmes should be used to perform human exposure assessment (including occupational health) and lead to regulatory enforcement mechanisms governing specific pesticide lifecycle within the "Farm to Fork" strategy. A regional action plan to strengthen food safety systems (2017-2022) (10) was developed by WHO and accepted by Member States to support this process.
However, while WHO continues to advocate a healthy and balanced diet for all, based on increasing portions of fresh fruits and vegetables, focus should also remain on the issue of pesticides residues. Moreover, adverse health effects of such chemicals are not immediately apparent but rather materialize over a human lifetime (from the moment of reproductive conception to the moment of demise, and perhaps even beyond when considering hereditary genetic mutation and distortion). An implementation and strict governance and enforcement of existing regulations and international agreements would be necessary to protect populations in the Region. Strengthening farmer education and proposing incentives to producers to implement good agricultural practices and integrated pesticide management remain the cornerstone to improving the situation in a sustainable way. Given the diverse mixtures of toxic substances, microbial agents and harmful compounds embedded within the pesticide application in agriculture, the risk of adverse health exposures throughout the production process cycle and beyond is very high. The role of national health and agricultural authorities must be concentrated on the health aspects of integrated chemicals and food safety throughout the life cycle, the safe and sound management of pesticides, as well consumers safety and well-being.

\section{References}

1. Khoso A, Wasim S, Zainab S. Prevalence and predictors of respiratory symptoms and illnesses among farmers: a cross-sectional survey, Pakistan. East Mediterr Health J. 2019;25(10):698-705. https://doi.org/10.26719/emhj.19.003 PMID: 31774135

2. Salem EA, Hegazy MM, El Khouley EA. Pesticide exposure as a risk factor for lymphoproliferative disorders in adults, East Mediterr Health J. 2014;20(6) 363-371. https://doi.org/10.26719/2014.20.6.363 PMID: 24960512

3. Salem AK, Abdulrab A, Alfakeh Y, Aown A. Hepatocellular carcinoma in Yemeni patients: a single centre experience over an 8-year period, East Mediterr Health J. 2012;18(7):693-699. https://doi.org/10.26719/2012.18.7.693 PMID: 22891515

4. Verger P, Agamy N, Anshasi M, Al-Yousfi AB. Occurrence of pesticide residues in Fruits and Vegetables for the Eastern Mediterranean Region and potential impact on public health. Food Control (8 July 2020, in press) https://doi.org/10.1016/j.foodcont.2020.107457

5. US Department of Agriculture (USDA). Pesticide Data Program's (PDP) 28th Annual Summary for calendar year 2018. Washington DC: USDA; 2019 (https://www.ams.usda.gov/sites/default/files/media/2018PDPAnnualSummary.pdf).

6. EFSA (European Food Safety Authority). Monitoring data on pesticide residues in food: results on organic versus conventionally produced food. EFSA supporting publication 2018:EN-1397:30 https://doi.org/10.2903/sp.efsa.2018.EN-1397.

7. UN Environment. Stockholm Convention, texts and annexes. Revised in 2017 on Persistent Organic Pollutants (POPS). Published by the Secretariat of the Stockholm Convention (SSC) in May 2018. (http://chm.pops.int/TheConvention/Overview/TextoftheConvention/tabid/2232/Default.aspx)

8. Al-Mandhari A. Achieving "Health for All by All" in the Eastern Mediterranean Region. East Mediterr Health J. 2019;25(9):595596. https://doi.org/10.26719/2019.25.9.595

9. World Health Organization. Joint Statement by FAO, WHO and WTO International Forum on Food Safety and Trade. Geneva: World Health Organization; 2019 (https://www.who.int/docs/default-source/resources/joint-statement.pdf).

10. Al-Yousfi AB; Bakir H; Malkawi M. The environmental health nexuses within the strategic roadmap: regional work priorities for the WHO Eastern Mediterranean Region. East Mediterr Health J. 2018;24(2):117-118. https://doi.org/10.26719/2018.24.2.117.

11. Coordinating Committee Near East (CCNE). Codex Alimentarius food standards. Tehran: CCNE; 2020. (http://www.fao.org/ fao-who-codexalimentarius/committees/codex-regions/ccne/about/en/).

12. Elmi M. Food Safety. East Mediterr. Health J. 2008;14(Special Issue) Suppl:S143-9.

13. Alwan A, Elmi M. Food safety in the Eastern Mediterranean Region: time to act. East Mediterr Health J. 2015;21(3) Suppl:153-4. https://doi.org/10.26719/2015.21.3.153 PMID:19205614 